DOI: 10.12731/2070-7568-2020-2-224-233

УДК 338.1

\title{
МЕТОДОЛОГИЯ МОДЕРНИЗАЦИИ СИСТЕМЫ УПРАВЛЕНИЯ НАУКОЕМКИМИ ПРЕДПРИЯТИЯМИ
}

\section{Сыщцикова Е.Н.}

В статье представлено описание ключевых принципов, обеспечивающих модернизаџию системы управления предприятием с позиций мировоззренческого, когнитивного и технологического аспектов; предложена логика проведения модернизации системы управления наукоемкими предприятиями.

Цель работы. Обосновать методологию модернизации системы управления наукоемким предприятием.

Метод или методология проведения работы. $B$ статье использованы следующие методы исследования: анализ и синтез, дедукция и индукция.

Результаты. Обоснована методология модернизаџии системы управления наукоемкими предприятиями.

Область применения результатов. Полученные результаты могут быть использованы при уточнении методических основ формирования систем управления наукоемкими предприятиями, ориентированными на устойчивое экономическое развитие.

Ключевые слова: модернизация; система управления; наукоемкое предприятие; когнитивные аспекты методологии; технологические аспекты методологии.

\section{METHODOLOGY \\ FOR MODERNIZING THE MANAGEMENT SYSTEM OF KNOWLEDGE-INTENSIVE ENTERPRISES}

\section{Syshchikova E.N.}

The article describes the key principles that ensure the modernization of the enterprise management system from the standpoint of worldview, 
cognitive and technological aspects; the logic of modernizing the management system of knowledge-intensive enterprises is proposed.

Objective. Substantiate the methodology for modernizing the management system of a knowledge-intensive enterprise.

Method or methodology of the work. The article uses such scientific methods as analysis and synthesis, deduction and induction

Results. The methodology of modernizing the management system of knowledge-intensive enterprises is substantiated.

Practical implications. The results obtained can be used to Refine the methodological basis for the formation of management systems for knowledge-intensive enterprises focused on sustainable economic development.

Keywords: modernization; management system; knowledge-intensive enterprise; cognitive aspects of the methodology; technological aspects of the methodology.

Рассматривая методологию в общем, в соответствии с подходом, предложенным Ю.И. Трещевским с соавторами, выделим три составляющих: мировоззренческую, когнитивную, технологическую $[4$, c. 8]. Этого подхода будем придерживаться в исследовании.

Как в отечественной так в зарубежной практике модернизации систем управления предприятием, существует некоторое множество подходов, которые имеют и функциональную и институциональную направленность.

Особое внимание в зарубежных источниках обращается на то, что модернизация системы управления предприятием должна иметь стратегически выраженный характер, т.е. основываться на проактивном видении внешнесредовых изменений и взаимосвязанных с ними внутрисредовых изменений (быть обращенной в будущее) [8].

Не вызывает сомнения, что между модернизационными и инновационными процессами имеется диалектическое противоречие модернизация призвана обновить уже существующие концепты и базы развития хозяйствующих субъектов, в то время как инновации призваны создавать нечто новое как в выпускаемой продукции (ис- 
пользуемых производственных технологиях), так и в организации управления предприятием.

Но, с другой стороны, ряд исследователей [1, с. 26-30; 7, с. 31-36] абсолютно верно отмечают, что инновационные и модернизационные процессы не только сопряжены, но и дополняют друг друга. Так, технологическая модернизация производства означает использование и технических улучшений, и технических нововведений. Аналогичным образом можно рассматривать и прочие направления (типы / виды) модернизации, в том числе и модернизации системы управления предприятием. Также направленность на совершенствование организационно-экономического механизма управления промышленными предприятиями приобретает особую значимость в условиях мирового экономического кризиса [6, с. 52-54].

Таким образом, очевидно, что инновационные и модернизационные процессы взаимосвязаны и взаимозависимы, а значит, могут быть комплексно использованы для в рамках обновления внутренней среды предприятий (реформирования системы и/или структуры управления) для достижения определенных целей, которая в нашем случае определяется как устойчивое экономическое развитие. Поэтому, основываясь на вышесказанном, можно говорить о том, что с одной стороны логика модернизации системы управления предприятием для достижения заявленных целей должна отталкиваться от потребностей самого предприятия в изменениях и обновлении, а с другой стороны - определять наиболее приоритетные направления этих изменений.

Учитывая вышесказанное, логика проведения модернизации системы управления предприятием должна основываться на потребностях самого предприятия в изменениях и обновлении. В свою очередь приоритеты мер по проведению модернизации должны исходить и из потребностей данного хозяйствующего субъекта к обновлению, и из способностей реализовать их.

Когнитивная составляющая методологии модернизации высокотехнологичных предприятий и организаций определяет способ получения знаний о проблеме $[4$, с. 8$]$. В рамках когнитивной со- 
ставляющей можно выделить понятие эффективности функционирования предприятия и принципы модернизации систем управления наукоемких организаций.

Если относиться к менеджменту как к процессу или деятельности по выработке, принятию и реализации управленческого решения, то его эффективность сводится к эффективному управлению данным процессом в организации [2, с. 269-272].

Таким образом, эффективность функционирования и развития наукоемких организаций (как результат или как отдача) может быть рассмотрена в социальном, экономическом и технологическом аспекте (рисунок 1).

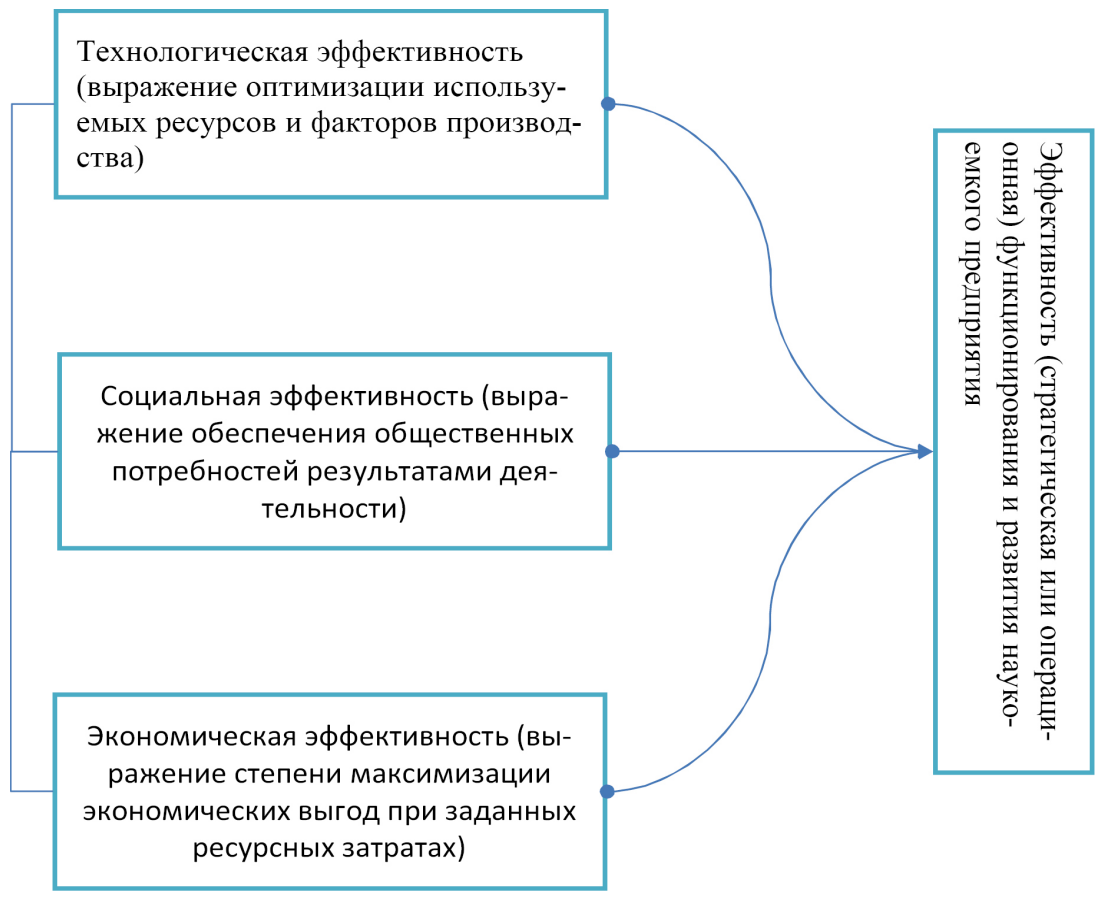

Эффективность функционирования и развития наукоемких организаций есть аналитико-оценочная управленческая категория, которая в общем случае может быть выражена через совокупность абсолютных или относительных показателей (имеющих стоимост- 
ное или ценностное выражение) в трех ключевых аспектах ведения деятельности: социальном, экономическом, технологическом.

Абсолютные показатели эффективности характеризуют уровень превалирования полученных выгод (соответственно, социальных, экономических или технологических) над затраченными для получения этих выгод ресурсами. Относительные показатели эффективности характеризуют степень достижения поставленных целей функционирования и развития наукоемких организаций с учетом фактически полученных результатов деятельности.

Таким образом, определение эффективности функционирования и развития наукоемких организаций должно инкорпорировать в себе различные теоретические подходы (иерархические, функциональные, ресурсные и прочие), а также рассматривать понятие «эффективность» в различных ракурсах. Это позволит более точно и более объективно сформировать методики оценки стоимости наукоемких организаций в современных условиях.

Далее необходимо перейти к определению модернизации системы управления. К общим принципам модернизации систем управления предприятиями относятся: принцип научной обоснованности; принцип системного подхода (паритетности); принцип регламентации и оптимальности; принцип формализации.

Среди частных принципов в рамках модернизации систем управления предприятиями стоит выделить следующие основные принципы:

1. принцип достаточности исходной информации;

2. принцип инвариантности информации;

3. принцип вариативности решения;

4. принцип преемственности;

5. принцип эффективной реализуемости;

6. принцип экономической выгоды.

Общие принципы модернизации системы управления предприятием могут быть применены как с макроэкономических, так и с микроэкономических подходов к изучению закономерностей функционирования и развития современных хозяйствующих субъектов, 
в том числе и наукоемких организаций. В свою очередь перечисленные частные принципы в большей степени могут быть успешно реализованы на уровне отдельно взятого предприятия.

Технологическая составляющая методологии модернизации высокотехнологичных предприятий и организаций определяет приемы исследования и применения на практике полученных знаний [4, с. 8].

По мнению Л.П. Пидоймо, полное исследование внешней и внутренней среды позволяет сформулировать комплекс мер и направлений, которые необходимо реализовать для модернизации системы управления предприятием [3, с. 18-23].

В технологическом аспекте модернизация системы управления предприятием может рассматриваться как комплекс стратегических и функциональных решений, основывающихся на аналитически обоснованном представлении закономерностей функционирования и развития конкретного хозяйствующего субъекта, его ближнего и дальнего окружения. Выработка стратегических и функциональных решений по проведению обновления внутренней среды предприятия должна характеризоваться рациональностью, т.е. соотносить действительные способности предприятия к изменениям, потребности в них и возможности внешней среды.

Модернизация управления любой организацией невозможна без анализа механизмов, соединяющих элементы предприятия между собой и рассмотрения специфики институциональных составляющих $[5$, с. 41-43].

На основании вышесказанного можно предложить концепцию логики модернизации системы управления предприятием для устойчивого экономического развития и роста стоимости наукоемких организаций. Построение логики и формулировка приоритетов модернизации системы управления предприятием необходимо начинать с формирования объективной аналитической основы, которая включает сведения и данные о состоянии внутренней среды предприятия (его подсистем управления) и о состоянии внешней среды предприятия (в социальном, экономическом, политическом и технологическом контексте). В общем случае, состояние внутренней 
среды необходимо интерпретировать как способности к проведению модернизации для достижения заявленной цели, состояние внешней среды - как возможности для практического приложения результатов модернизации.

Сопоставление возможностей внешней среды (которые могут быть достаточными, сокращенными или отсутствовать) со способностями внутренней среды (которые также могут быть достаточными, сокращенными или отсутствовать) формирует баланс сил, угроз и рисков проведения модернизации. В том случае, когда и возможности внешней среды, и способности предприятия к модернизации отсутствуют, наиболее правильным решением будет ликвидация предприятия или полное его реформирование (вплоть до слияний и поглощений). Но, как правило, у любого, даже кризисного предприятия имеются скрытые резервы развития, которые необходимо изыскать и использовать для модернизации системы управления предприятием.

Соответственно, выявленные возможности и идентифицированные способности предприятия к проведению модернизации образуя аналитико-эмпирическую базу, позволяют конкретизировать перечень мер, которые требуют реализации. И здесь в общем случае стоит выделять меры: организационного, экономического и / или технико-технологического характера:

- в первом случае модернизации подвергается локальное нормативное регулирование деятельности предприятия, а также организационная структура управления;

- во втором случае модернизация направлена на устранение потерь ресурсов и изыскание их новых источников для максимизации выгод;

- в третьем случае модернизация направлена на физическое и нематериальное обновление активов, эксплуатация которых позволяет получать предприятию те или иные выгоды.

На основании созданного перечня мер осуществляется расстановка приоритетов решений по модернизации системы управления предприятием. И здесь, в зависимости от того, какими способностями обладает предприятие и каковы возможности внешней среды может быть: 
- параллельная реализация решений (одновременная модернизация всех подсистем);

- последовательная реализация решений (поэтапная модернизация всех подсистем).

Если способности предприятия к проведению модернизации в достаточной степени широкие и, кроме этого, возможности внешней среды не имеют существенных ограничений, целесообразно использовать параллельную реализацию решений с одновременной модернизацией всех подсистем. В том случае, когда способности предприятия несколько сокращены, а возможности в определенной мере ограничены, целесообразно использовать последовательную реализацию решений с проведением поэтапного мониторинга результатов реализации мер, направленных на обновление системы управления.

В общем случае контроль реализации мер и решений, связанных с проведением модернизации системы управления предприятием, должен иметь целевую направленность, а именно - идентифицировать устойчивое экономическое развитие. Если результатом реализации мер является объективный прирост устойчивого экономического развития и роста стоимости наукоемких организаций, то в данном случае предприятию необходимо формулировать новую стратегию развития на среднесрочный и долгосрочный период.

В свою очередь если отсутствует прирост стоимости наукоемких предприятий, то соответственно необходимо проведение более полного и глубокого аналитического исследования, в том числе касающегося качества реализации мер по модернизации системы управления предприятием. В данном случае целесообразен возврат к идентификации способностей предприятия и имеющихся возможностей в рамках модернизационных процессов.

В результате проведенного исследования, в рамках мировоззренческих аспектов рассмотрена природа модернизации системы управления предприятием для устойчивого экономического развития и роста стоимости наукоемких организаций.

В рамках когнитивных аспектов методологии представлено описание ключевых принципов, обеспечивающих модернизацию системы управления предприятием. В работе выделено четыре общих и 
порядка шести частных принципов совершенствования указанных систем. Общие принципы структурируют регламентацию действий в рамках модернизации систем управления, частные принципы определяют требования к организации управленческой деятельности для достижения необходимых результатов.

В рамках технологических аспектов методологии предложена логика проведения модернизации системы управления предприятием, которая имеет алгоритмизированный вид, что в свою очередь означает определенную последовательность действий, при этом контроль и мониторинг результатов модернизации, который должен носить целевой характер, т.е. определять действительный прирост стоимости наукоемких организаций на фоне реализуемых мер и решений.

\section{Список литературы}

1. Арзамасова Н.П., Комков Н.И., Лазарев А.А. Проблемы и условия инновационной модернизации предприятия // МИР (Модернизация. Инновации. Развитие). 2012. № 8. С. 26-30.

2. Макарова Е.Е. Теоретические аспекты стратегического менеджмента // Современные исследования социальных проблем. 2012. № 1-2. С. 269-272.

3. Пидоймо Л.П. Факторы и модель модернизации наукоемких организаций // Вестник ВГУ. 2010. №12. С. 18-23.

4. Ромащенко Т.Д., Трещевский Ю.И., Трещевская Н.Ю. Методология научного исследования экономики, управления и финансов. Воронеж, 2009. С. 8.

5. Сыщикова Е.Н. Модернизация организационной структуры управления промышленным предприятием // Экономинфо. 2010. № 13. С. 41-43.

6. Сыщикова Е.Н. Содержание организационно-экономического механизма управления предприятием // Вестник Воронежского государственного технического университета. 2011. Т. 7. № 5. С. 52-54.

7. Трофимов О.В., Трофимова Т.В. Новая концепция стратегического управления предприятиями в современных условиях. // Креативная экономика. 2010. №3. С. 31-36.

8. Enterprise modernization: A Rational approach // IBM Software Thought Leadership White Paper. July, 2011. 


\section{References}

1. Arzamasova N.P., Komkov N.I., Lazarev A.A. MIR (Modernizatsiya. Innovatsii. Razvitie). 2012. № 8, pp. 26-30;

2. Makarova E.E. Sovremennye issledovaniya sotsial'nykh problem. 2012. № 1-2, pp. 269-272.

3. Pidoymo L.P. Vestnik VGU. 2010. №12, pp. 18-23.

4. Romashchenko T.D., Treshchevskiy Yu.I., Treshchevskaya N.Yu. Metodologiya nauchnogo issledovaniya ekonomiki, upravleniya i finansov [Methodology of scientific research of economics, management and finance]. Voronezh, 2009. P. 8.

5. Syshchikova E.N. Ekonominfo. 2010. № 13, pp. 41-43.

6. Syshchikova E.N. Vestnik Voronezhskogo gosudarstvennogo tekhnicheskogo universiteta. 2011. V. 7. № 5, pp. 52-54.

7. Trofimov O.V., Trofimova T.V. Kreativnaya ekonomika. 2010. №3, pp. 31-36.

8. Enterprise modernization: A Rational approach // IBM Software Thought Leadership White Paper. July, 2011.

\section{ДАННЫЕ ОБ АВТОРЕ}

Сыщикова Елена Николаевна, заведующий кафедрой «Экономики и управления недвижимостью», кандидат экономических наук, доцент

Российский государственный университет правосудия

ул. Новочеремушкинская, 69, г. Москва, 117418, Российская Федерация

syshhikova.elena@mail.ru

\section{DATA ABOUT THE AUTHOR}

Syshchikova Elena Nikolaevna, Head of the Department of «Economics and Real Estate Management», Candidate of Economics, Associate Professor

Russian State University of Justice

69, Novocheremushkinskaya St., Moscow, 117418, Russian Federation syshhikova.elena@mail.ru

SPIN-code: 6017-1081 